\title{
Effective E-Challan Generation and Management System for RTO
}

\author{
Praful R. Pardhi ${ }^{*}$, Pravinkumar M. Sonsare ${ }^{2}$ and Aditya Jain ${ }^{3}$ \\ 1,2Department of Computer Science and Engineering, Shri Ramedobaba \\ College of Engineering \& Management, Nagpur, India \\ ${ }^{3} P G$ Scholar, Computer Science, IIT, Bombay, India
}

\begin{abstract}
With increasing incidents, the need for monitoring the roads to avoid mishaps is also increasing. Thus, today we see police officers keeping a strict vigilance and compelling the citizens to follow the rules by imposing a fine or challan. But in this system, there is a delay in the processing of challan due to which the citizens tend to continue with their recklessness. Thus, there is a need to make this challan system more effective and ease the job of the police officials. This can be achieved through an android application which aids instant payment of challan. Existing RTO Office work is very complex, time-consuming \& having real-life problems such as if an individual needs to pay the challan, every time he/she needs to visit the RTO. This takes a lot of time. And nowadays each and every person is in hurry so by analyzing and considering these problems we developed a mobile application which overcomes this problem and gets a solution in an effıcient way.
\end{abstract}

KEY WORDS: RTO, FIREBASE, E-CHALLAN, E-SEVA ETC.

\section{INTRODUCTION}

e-Challan is an electronic format of the challan, a term generally used in India and Pakistan as a receipt for payment or delivery. An e-Challan can also be defined as a specific format used for depositing or remitting the contribution or statutory payment at a bank or treasury. A challan is a way of crediting the money to one's bank account through a form. An example of a challan would be a spot traffic ticket issued by the traffic police for a violation of traffic rules. This challan would then have to be paid directly by cash, at an e-Seva center, or by any other payment mode as specified on the challan.

\section{ARTICLE INFORMATION}

Received 20th Oct 2020 Accepted after revision 31st Dec 2020 Print ISSN: 0974-6455 Online ISSN: 2321-4007 CODEN: BBRCBA

Thomson Reuters ISI Web of Science Clarivate Analytics USA and Crossref Indexed Journal

\section{Clarivate
Analytics}

\section{crossef}

NAAS Journal Score 2020 (4.31) SJIF: 2020 (7.728)

A Society of Science and Nature Publication,

Bhopal India 2020. All rights reserved.

Online Contents Available at: http//www.bbrc.in/

Doi: http://dx.doi.org/10.21786/bbrc/13.14/16
This system is helpful for Traffic police also as it helps traffic police to be more effective in controlling repeat violators of traffic rules. Traffic Police have the database of registration numbers as well as the history of driving license holders. When a traffic policeman would enter the details of any vehicle caught violating traffic rules, it would give the complete details of that particular vehicle including the name and address of the owner and the make, model, and other details of the vehicle. Not only this, but the details of the driving license holder would also be available. Therefore enhanced penalties would be imposed for the repetition of violation of traffic rules. Fake registration plates, if any, would be detected immediately.

\section{Objectives}

The proposed application aims

- To take input as a picture or as the vehicle number for which the challan will be generated.

- To send a text message and a notification regarding the payment of challan.

- To aid the driver to pay the challan through online payment.

- To ease identification and notification in case of 
accidents.

- $\quad$ To trace the missing vehicle.

- To create an enhanced web application to be used in place of old system.

- To Provide easiest and efficient way to handle the hassles work of RTO.

- To ensure transparency in the day-to-day management and administration of the officials in RTO department.

\section{Systems/Technologies used}

- Application development: Android Studio, Java \&t XML

- Database Management: SQL, SQLite \& Firebase Real-time Database.

- Location based services: Google Maps API services.

Propose Approach: Proposed approach designed a mobile application with an interactive user interface, designed and setup the database connectivity using SQLite $\&$ Firebase real-time database, implement Location Based Services to get the location at real-time and testing of application with all aspects. Implementation requires:

- Connection with online database:

- Uploading important documents.

- Login Page Functionality.

- Dynamic fetching of location.

- Online payment of challan.

Methodologies: The complete work is divided into three categories of users which are Admin (RTO), Traffic police, and the general public. The various situations in which the app can be helpful are:

- Generating Challan

- Notifications in case of accidents

Generating Challan: In this situation, the police officer will have access to click the image of a person caught without the helmet and will have to enter the vehicle number. After entering the number, the police will get complete information of the user which includes his account of previously paid challan. The police can then generate a new challan which will get added to the RTO database. The RTO will then have to update the current profile of the user and will have to notify the user. After getting notified, the user will have two options to pay the challan:

1. Online payment using the app

2. Pay at RTO

Once the payment is successful, the user's profile will get updated by the RTO and will receive the confirmation message. In case, the user is not done with the payment, the user will constantly get notified in specified duration.

Notification in case of accidents: At the time of registration, the user will have to provide 3-5 contact numbers that he would like to get notified in case of emergency. If a person is met with an accident, the witness will be able to notify the person the victim has registered. The app will be provided with a feature using which, the witness will have to enter the victim's vehicle number. On entering the number, the list of the registered contacts will get displayed, which will then get notified about the incident along with the location of the mishap. The notified person can then contact the witness to get information about the incident and further updates.

Three main Modules of an application are:

1. User

2. Police

3. RTO (Database)

Figure 1: Use-case diagram for Challan management System

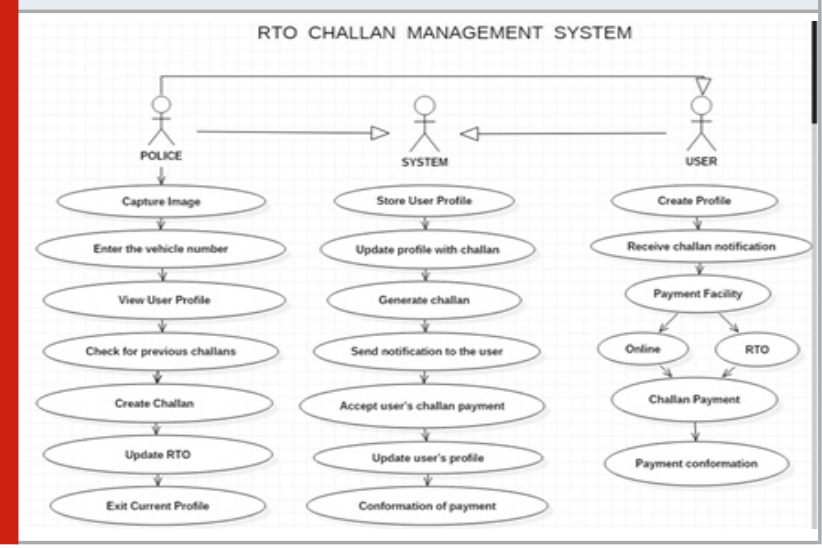

Figure 2: Dataflow Diagram of Online Challan Generartion ft Mangement System.

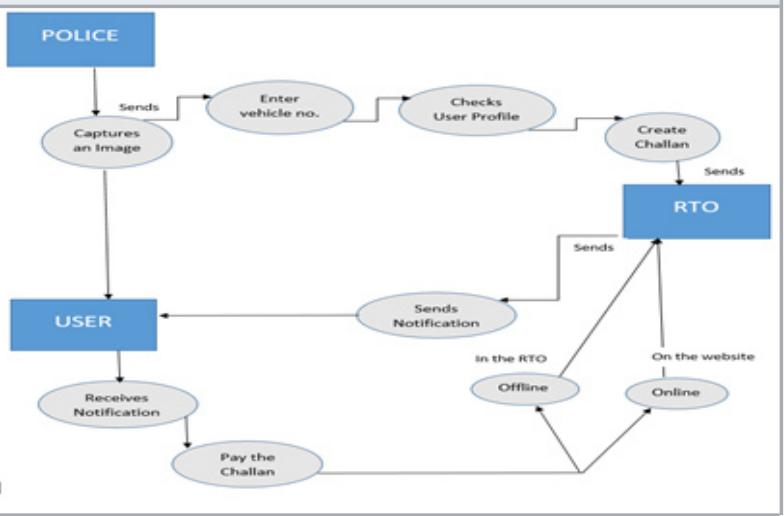

User Domain: The User Domain is for the general public who will be given a unique password by the RTO while registering. Through this account, the user will be able to perform the following functions

- Online payment of challan

- Viewing challan details (paid or unpaid)

- Reporting accident

- Editing profile

- Uploading documents (such as Driving license, Aadhar card, PAN card etc.)

Functionalities available for user: The above mentioned are some important functions that the user (i.e. general 
public) of the application can perform. Once the user logs in in his/her account, he will be directed to the home page which will display the username and his vehicle number. The user will also need to verify the OTP first time through the email ID. As you can see it has three main functions. Let's take a broader look at each functionality.

Challan Details: On pressing the Challan details button on the home screen the user will be able to view the history of challan payments till date and also the challan to be paid. The challan details for a paid challan will consist of the date of generation of challan, date of payment, amount, and the location where the rule-breaker was fined.

Online Challan Payment: Through this feature users are allowed to do the online payment for the challan through the e-payment services which minimize the physical as well as time-overhead of the user.

Report Accidents: In case an accident takes place in front of a user then he can report the accident by logging into his account and selecting the report accident button. On hitting the button, the user will be asked to enter the vehicle number of the victim. On hitting the search button, the profile of the victim will be displayed along with three contacts of his relatives. On hitting the send notification button, the message of the mishap will be sent to the three contacts along with the location of the accident.

In this manner the victim will get immediate medical aid through their relatives. In addition to these three major features there are some more features which include editing of the profile, adding emergency contacts, and uploading documents such as Aadhar card, driving license, and vehicle registration documents.

Police Domain: Police domain act as the intermediate between the User and the RTO. The main role of the police domain is to generate challan. Police will be able to generate the challan of the user in case if any user breaks the rule. The police application helps to generate instant challan which eases the work of the traffic police. Features included in this module are.

- View details of a rule breaker

- Generate challan instantly

- Verify the documents of the user

- Gets notified time to time from the RTO

- To inform the victim's relative in case of any accidental issues

How Police domain works: The traffic police will initially get an email id and password from the RTO. Through this mail id and password, the police will be able to login to his own application module. This is nothing but giving security to the application so that no one else other than traffic police will be allowed to login to the system. As soon as he logs in into the system he will be able to capture the image and generate the challan.
How Challan Is Generated By Traffic Police: As soon as the rule breaker is caught by the traffic police officer, he will need to enter the vehicle number into the application and capture a photograph of the number plate which will act as a proof that the vehicle was actually caught by the police. As soon as he proceeds further the challan gets generated for the respective vehicle number entered. The challan generated by the police gets updated to the RTO instantly. The user will also get notified about challan which is generated by the police.

Other Functionality of Police Domain: The police have additional functionality i.e. he can inform about any accidental issue occurred nearby. He just has to enter the victim's vehicle number in the required field and press enter. The registered mobile numbers of the victim will be displayed and the message will be sent to all the numbers. The other functionality of the police is that he can view the documents of the user. Through this, the police can warn the user about the pending challan (if any) while generating a new challan. This will generate awareness among the public that they have to pay the pending challan also (in case if the user forgets to pay any challan). The police will also, be able to check whether the user has valid documents or not. When any user is being caught by the police officer, he will be able to check that the user has the valid documentation of the vehicle or not.

RTO (Database): The RTO system is nothing but the database which is handled by the RTO office. The RTO office maintains a database that consists of all the information about the vehicles being purchased and being registered. The RTO maintains the database in a real-time manner so that instant challan's can be generated and notified. Various features included in this module are.

- Managing the database

- Save data in real time manner

- Provide details to the traffic police as and when needed

- Provide emergency contacts of the victim to the traffic police

- Provide necessary notification to the traffic police

- $\quad$ RTO keeps record of the registered vehicles

- Update the user domain as per the challan paid or not

How the RTO System Process: The RTO system simply maintains the database which consists of all the information of the registered vehicle. The RTO gets updated in a real-time environment and also provides the necessary information to the traffic police whenever required. As soon as the request comes from the police domain the RTO system processes it and provides the required information. The RTO system (database) consists of the emergency contacts feed into it. The emergency contacts are provided by the user while registration of the vehicle at the RTO. At the very early stage, the contacts 
are stored in the database which is useful when any of the emergency cases occurs.

In emergency case (i.e. accident) when the police or any user enter the victim's vehicle number in their respective application then the request is directly sent to the RTO system to fetch the data and provide the contact number. The RTO verifies the vehicle number and provides the contact number to the police or user. If the number is not found in the database then no further information is provided by the RTO. The RTO helps in maintaining the record of the registered user.

Firebase Real-time Database: Store and sync information with our NoSQL cloud information base. Information is matched up over all customers in real-time and stays accessible when your application goes disconnected The Firebase Real-time Database is a cloud-facilitated information base. Information is put away as JSON and synchronized in real-time to each connected client. At the point when you assemble cross- platform applications with our iOS, Android, JavaScript, and SDKs, the entirety of your clients share one real-time Database occurrence and naturally get refreshes with the most current information. After each violation, the profile of the defaulter will be created. In case a person cannot pay the fine on the spot, he can pay it online by logging on to the website. The challan receipt issued will have a unique identification number. Entering this number will take the defaulter to his profile which will have a history of violations by him.

\section{RESULTS}

Proposed work has resulted in a working application that will help the Police Department, the citizens, and the RTO to conjointly contribute in making our city safe. It is a fully functional application that will allow the citizens to upload their documents such as Aadhar card, driving license, etc, approved by the RTO. The Challan payment will be strictly monitored through the app thereby making the system more meticulous. In case of an accident, the victim will be provided with immediate help by reaching their near and dear ones within minutes which could give him/her a new life.

\section{CONCLUSION \&E SCOPE}

RTO Challan Management System is a mobile-based application, which is very useful for RTO works completely online. Here we have developed the modules which help to reduce the RTO work manually and it helps to save the time of the user. Considerably reduce corruption in the transport department. Very useful for the completion of RTO work online. Our system helps R.T.O Officers to perform their functions electronically. It will also help the R.T.0 officials to maintain records systematically and reduces a lot of paperwork and manual efforts. We also identified some general requirements of such a system and tried to meet those requirements as much as possible in the design and implementation of our system. Traffic policemen can easily generate challans and update it instantly in the RTO database system.

In the future, as per the user's requirement, the work can be extended and it provides a better way of document verification for R.T.O officials. Our system is an integration of several systems that in the present act as a separate system. It will also reduce a lot of clerical works and provides better accountability. We can also add a provision to track a stolen vehicle in the future systems either through verification or through GPS tracking. This system is also helpful for Traffic police also. The traffic police to be more effective in controlling repeat violators of traffic rules. Therefore enhanced penalties would be imposed for the repetition of violation of traffic rules. Fake registration plates, if any, would be detected immediately.

\section{REFERENCES}

Alpana Gopi, Litty Rajan, Divya P R, Surya Rajan (May -2017) E-RTO Management System and Vehicle Authentication Using RFID”, IRJET, Volume: 04 Issue: 05,

Jayshree , Vilas Tijare, Upendra Ramteke, Devashish "E-RTO MANAGEMENT SYSTEM " In IJRISE ISSN: 2394-8299 Special Issue: TechnoXtreme 16.

Manjunath S Patil, Basavaraj K Madagouda, Vinod C Desai (July - 2013) E-RTO Management System" In IJERT ISSN: 2278-0181 V2IS70177 Vol. 2 Issue 7.

Prof. Ansar Sheikh, Shivani Makde, Khushbu Akare, Nikita Dongre ,Shrddha Malve, Rohini Mankar "Implementation of Online Regional Transport Office Management System”, JETIR May 2020, Volume 7, Issue 5

Songkran Kantawong , Tanasak Phanprasi "Vehicle Accident Detection And Identification Using Image Compression Analysis And RFID”.

Saritha M, Rajalakshmi S, Angel Deborah S, Milton R S Thirumla Devi S, Vrithika M, Krishnap Priya G B "RFID-Based Traffic Violation Detection and Traffic Flow Analysis System” International Journal of Pure and Applied Mathematics, Volume 118 No. 20 2018, 319-328 